\section{SMGrøup}

SM

\section{Musculoskeletal Disorders}

Article Information

Received date: Aug 31, 2018

Accepted date: Sep 18, 2018

Published date: Sep 21, 2018

${ }^{*}$ Corresponding author

Steven A Lavender, Department of Integrated Systems Engineering, The Ohio State University, USA, Email: Lavender.1@osu.edu

Distributed under Creative Commons CC-BY 4.0

Keywords Lower Extremities; Musculoskeletal Disorders; Distribution Centers; Material Handling; Leg Pain

Article DOI 10.36876/smmd.1029

\title{
The Prevalence of Lower Extremity Musculoskeletal Disorder Symptoms in Retail Distribution Centers
}

\author{
Mohini Dutt ${ }^{1}$, Steven A Lavender ${ }^{1,2}$, Carolyn M Sommerich ${ }^{1}$ and Ajit MW \\ Chaudhari $^{2,3}$ \\ ${ }^{1}$ Department of Integrated Systems Engineering, The Ohio State University, USA \\ ${ }^{2}$ Department of Orthopedics, The Ohio State University, USA \\ ${ }^{3}$ Health and Rehabilitation Sciences, The Ohio State University, USA
}

\section{Abstract}

In our prior studies of distribution center workers, we found that participating companies' injury logs contained very few reported lower extremity Musculoskeletal Disorders (MSDs), yet a significant percentage of workers reportedly had experienced knee pain. In this study, 341 workers performing material handling jobs from three distribution centers completed a questionnaire that assessed lower extremity MSD symptoms. Two-thirds of the participant's self-reported work-related lower extremity musculoskeletal symptoms. These were most common in the ankles and feet, followed by knees and hip \& thighs. Approximately half the sample experienced pain on work days and some on a daily basis. A large percentage of the respondents reported that their symptoms were exacerbated by work. Stand-up forklift drivers had the highest 12-month prevalence of knee and ankle/foot symptoms across the occupations included in this sample. Significant associations were also found between symptoms and age, gender, work experience, and smoking status.

\section{Introduction}

The US Bureau of Labor Statistics (BLS) reports that amongst private sector industries, the Transportation and Warehousing sector has the highest incidence rate of musculoskeletal disorders. In 2014, laborers and freight, stock and material movers had one of the highest incidence rates of overexertion injuries. Of all non-fatal lost time injuries reported, lower extremities were the second most frequently injured part of the body [1].

In distribution center environments, workers are exposed to excessive walking on hard surfaces [2], stepping up or down between work surfaces, and vibration exposure while riding material handling equipment such as forklifts and pallet jacks. These workers are also often involved in handling heavy cases of products and working at a rapid pace [3-5].

Prior studies have shown associations between material handling and the development of lower extremity musculoskeletal disorders. Messing et al. [6] studied the association between working posture (several specific standing conditions $v s$. "sitting with the option to get up at will") and "clinically significant" lower leg pain in a working population. Their logistic regression models showed an increased risk for all standing work postures when compared with the reference condition. These authors also reported that handling heavy loads all the time was an additional risk factor for calf/leg pain in women and exposure to whole body vibration all the time was an additional risk factor for calf/leg and ankle/foot pain in men.

Andersen et al. [7] studied cumulative lifting and pushing or pulling material handling tasks, which were associated with both lower back (cumulative lifting) and lower extremity (cumulative pushing or pulling) discomfort. An increased risk of hip, knee, and foot pain was found for people who push or pull a cumulative load of more than $355 \mathrm{~kg}$ per hour.

Previous studies have linked hip pain and osteoarthritis to biomechanical loading exposures in selected occupations. Vingard et al. [8] found that workers in occupations that experienced greater static and dynamic loads on the lower extremity, such as farmers, construction workers, firefighters, grain mill workers, butchers, and meat preparation workers, showed an increased risk of hip osteoarthritis. Pope et al.[9] reported an association between individuals who were lifting and moving materials weighing $23 \mathrm{~kg}$ or more and hip discomfort complaints. Similarly, Sobti et al. [10] reported a significant association between lifting greater than $25 \mathrm{~kg}$ ( $55 \mathrm{lb}$ ) per item per average workday and the occurrence of hip discomfort. This significant association, along with back pain symptoms, according to Pope et al. [9], was stronger in individuals who had performed lifting tasks at work for more than 20 years. 
Increased knee osteoarthritis has been reported in occupations that involved increased frequency of knee movement [11,12], especially in the older population. McGlothlin [13] showed that beverage delivery personnel not only reported discomfort in their backs and shoulders, but also in their knees.

deZwart et al. [14] reported an increase of ankle and foot complaints in men 40 to 49 years of age who had jobs with heavy physical demands as compared to those in younger age groups. Dawson et al. [15] studied women in the age group of 50 to 70 years and reported foot pain in individuals who had spent a greater number of years in occupations where they lifted material regularly.

In sum, the literature shows an association between occupational exposures similar to those in distribution center environments and the development of occupational lower extremity MSD symptoms. The overall goal of the current study was to assess the magnitude of this problem in retail distribution operations by assessing the selfreported prevalence of MSD symptoms in four different regions of the lower extremities- hip/thighs, knees, lower legs, ankle/feet amongst material handlers working in these environments.

\section{Methods}

This research was conducted at two general merchandise and one grocery distribution center in Ohio. At each facility, workers were recruited to complete a lower extremity symptom survey. Data collected from the three distribution centers were pooled for the final analysis.

\section{Subjects}

Participants were recruited from the population of employees at three retail Distribution Center (DC) locations who were 18 years or older and had worked for their distribution center for at least one month. Across the three DCs, 349 full-time employees, aged 18 years or older, who performed material handling jobs volunteered to participate in the study. Of these, 343 participants completed the survey. Six volunteers did not complete the survey. Two completed surveys were from trainees and they were not included in the analysis, thereby reducing the sample to 341 . As for the remaining 341 participants, 255 (75 percent) were male, and 86 (25percent) were female. The sample had a mean height of $1.80 \mathrm{~m}(\mathrm{sd}=0.1 \mathrm{~m})$ and weight of $96.1 \mathrm{~kg}(\mathrm{sd}=20.9 \mathrm{~kg})$ for males and a mean height of $1.65 \mathrm{~m}(\mathrm{sd}=0.1 \mathrm{~m})$ and weight of $82.5 \mathrm{~kg}(\mathrm{sd}=22.1 \mathrm{~kg})$ for females. The participating employees worked, on average 41 hours per week (sd=5.5 hours). Survey participants performed different material handling jobs throughout the distribution center in the Receiving, Order Picking and Shipping departments. The distribution of job tenure, age, and BMI are summarized in+ Table 1. A subset of participants from each of the different jobs sampled volunteered to wear a pedometer for two hours of their work shift. These devices were worn by 100 males and 33 females.

\section{Data collection procedures}

Participants were recruited during employee start-of-shift meetings. Those choosing to participate provided informed, written consent. The survey, comprised of five sections, queried participants about demographic information, health behaviors, employment history, and musculoskeletal health. The Nordic Musculoskeletal
Questionnaire was used for the musculoskeletal health portion of the survey. The three DCs allowed their employees to complete the survey on company time at the start of the shift. The protocol was approved by The Ohio State University's Institutional Review Board.

\section{Data Analysis}

Descriptive statistics were generated for each survey item. Overall means and frequencies were used to examine the prevalence of lower extremity work related musculoskeletal symptoms by: (a) anatomical region (hip \& thigh, knees, lower legs, and ankles \& feet); (b) age; (c) job tenure; (d) gender; (e) smoking status; and (f) BMI.

Additionally, based on the driving and walking activities in these jobs, the jobs were classified into the following four groups depending on whether they were walking large or small distances and whether they were driving equipment such as forklifts and pallet jacks. The classification scheme is shown in Table 2.

Prevalence was calculated by dividing the number of participants in the category who experienced a symptom (ache, pain, discomfort, burning, numbness, tingling, or other trouble) within the last year by the total number of survey respondents.

Pedometer data were transformed into a rate of steps per hour. A comparison across job types was done using an analysis of variance.

Table 1: Age, BMI, and Job Tenure of the participating distribution center employees.

\begin{tabular}{|c|c|c|}
\hline Sample Characteristic & Frequency & Percentage \\
\hline \multicolumn{3}{|l|}{ Age $($ mean $=36.3$ years, $s d=12.1$ years $)$} \\
\hline $18-25$ years & 85 & $24.90 \%$ \\
\hline $26-35$ years & 98 & $28.70 \%$ \\
\hline $36-45$ years & 72 & $21.10 \%$ \\
\hline $46-55$ years & 56 & $16.40 \%$ \\
\hline 56 years or older & 28 & $8.20 \%$ \\
\hline \multicolumn{3}{|l|}{ Weight $($ mean $=88.0 \mathrm{~kg}, \mathrm{sd}=20.9 \mathrm{~kg})$} \\
\hline Males $($ mean $=92.2 \mathrm{~kg}, \mathrm{sd}=20.5 \mathrm{~kg})$ & & \\
\hline \multicolumn{3}{|l|}{ Females $($ mean $=79.9 \mathrm{~kg}, \mathrm{sd}=17.7 \mathrm{~kg})$} \\
\hline \multicolumn{3}{|l|}{ Height $($ mean $=1.76 \mathrm{~m}, \mathrm{sd}=0.1 \mathrm{~m})$} \\
\hline \multicolumn{3}{|l|}{ Males $($ mean $=1.79 \mathrm{~m}, \mathrm{sd}=0.1 \mathrm{~m})$} \\
\hline \multicolumn{3}{|l|}{ Females $($ mean $=1.65 \mathrm{~m}, \mathrm{sd}=0.1 \mathrm{~m})$} \\
\hline BMI Underweight $(<18.5)$ & 1 & $0.30 \%$ \\
\hline Normal (18.5-24.9) & 97 & $28.40 \%$ \\
\hline Overweight (25-29.9) & 124 & $36.40 \%$ \\
\hline Obese $(>30)$ & 111 & $32.60 \%$ \\
\hline \multicolumn{3}{|l|}{ Job Tenure (mean 6.4 years, sd = 6.8 years) } \\
\hline 1.0 year or less & 103 & $30.20 \%$ \\
\hline $1.1-5.0$ years & 96 & $28.20 \%$ \\
\hline $5.1-10.0$ years & 41 & $12.00 \%$ \\
\hline 10.1-15.0 years & 45 & $13.20 \%$ \\
\hline 15.1-20.0 years & 41 & $12.00 \%$ \\
\hline 20.1 years or more & 14 & $4.10 \%$ \\
\hline
\end{tabular}


Table 2: Job type classifications

\begin{tabular}{|c|c|c|}
\hline Category Name & Jobs included & Description \\
\hline $\begin{array}{c}\text { Driving (Forklift) } \\
\mathrm{n}=44 \text { (males }=41 \\
\text { females }=3 \text { ) Avg. } \\
\text { Age=39.4 (s.d.=10.5 yrs.) }\end{array}$ & $\begin{array}{c}\text { Replenishment/put-away } \\
\text { drivers }\end{array}$ & $\begin{array}{l}\text { Drive stand-up forklifts in the warehouse area of the D.C. Typically use left foot to get off the forklift. } \\
\text { Activities typically include replenishing pallets in pick areas and driving material from receiving dock to } \\
\text { storage locations. }\end{array}$ \\
\hline $\begin{array}{c}\text { Driving (Pallet Jack) } \\
\mathrm{n}=93 \text { (males }=81 \\
\text { females=12) Avg. } \\
\text { Age }=34.1 \text { (s.d.=11.5 yrs.) }\end{array}$ & $\begin{array}{l}\text { Pick to pallet operators, } \\
\text { Receiving trailer } \\
\text { unloaders, } \\
\text { Shipping pallet loaders }\end{array}$ & $\begin{array}{l}\text { Drive pallet jacks for order picking, receiving or shipping. Use right foot to step down from equipment. } \\
\text { Driving pallet jacks for pick to pallet operations requires operator to step on and off the pallet jack as they lift } \\
\text { material from storage location on to shipping pallets. } \\
\text { Receiving trailer unloaders remove pallets from trailers and place on the receiving dock. This requires } \\
\text { repeated going in and out of trailers over dock plates. } \\
\text { Shipping pallet loaders move non-conveyable items that are pick to pallet into shipping trailers. }\end{array}$ \\
\hline $\begin{array}{c}\text { Walking (Large Area) } \\
\mathrm{n}=69 \text { (males }=37 \\
\text { females }=32) \text { Avg. } \\
\text { Age }=33.8 \text { (s.d. }=11.5 \text { yrs. })\end{array}$ & $\begin{array}{l}\text { Pick to belt, } \\
\text { Pick to tote }\end{array}$ & $\begin{array}{l}\text { In the Pick to belt job, individual items are picked from pallet and loaded directly loaded in the conveyor or } \\
\text { trailer. } \\
\qquad \begin{array}{l}\text { In the Pick to tote job, small individual items were picked and filling totes. } \\
\text { Both jobs require walking large areas. }\end{array}\end{array}$ \\
\hline
\end{tabular}

\section{Results}

\section{Symptom prevalence by anatomical region}

Two hundred and twenty-six participants (66.3 percent) reported that they had experienced symptoms in one or more regions of the lower extremity in the 12 months preceding the survey. The highest prevalence of symptoms was reported in the ankles and feet (43.4 percent), while approximately a third of the participants reported symptoms in the hip \& thighs or the knees (Figure 1).

Eighty-three participants reported symptoms in one region and 143 participants had symptoms in more than one region. Figure 2 provides the frequency distribution of the anatomical regions affected by the number of the lower extremity regions affected in each individual.

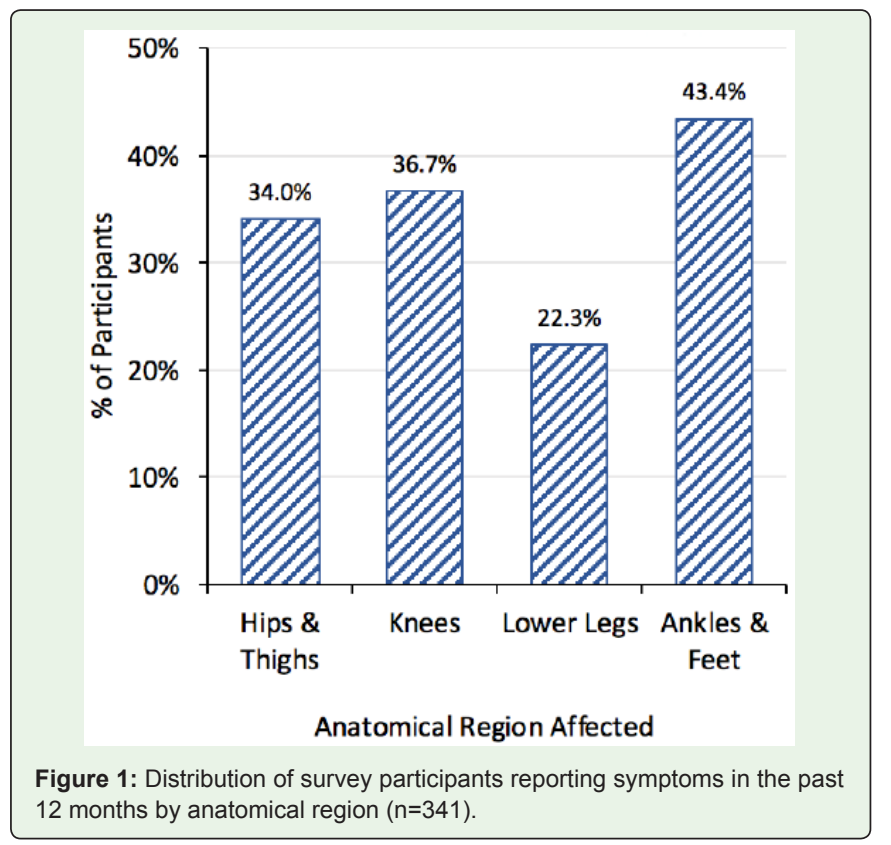

Participants who reported symptoms in a particular region of their lower extremities responded to questions pertaining to frequency, cause, intensity and changes made due to the symptoms. Figure 3 summarizes the distribution of responses to the questions, by those individuals who reported symptoms in the hip \& thighs, knees, lower legs, and ankle \& feet.

Approximately half the participants, who indicated hip, knee, lower leg, and foot/ankle symptoms experience their symptoms either daily or on the days that they work (Figures 3 a-d). Only a small

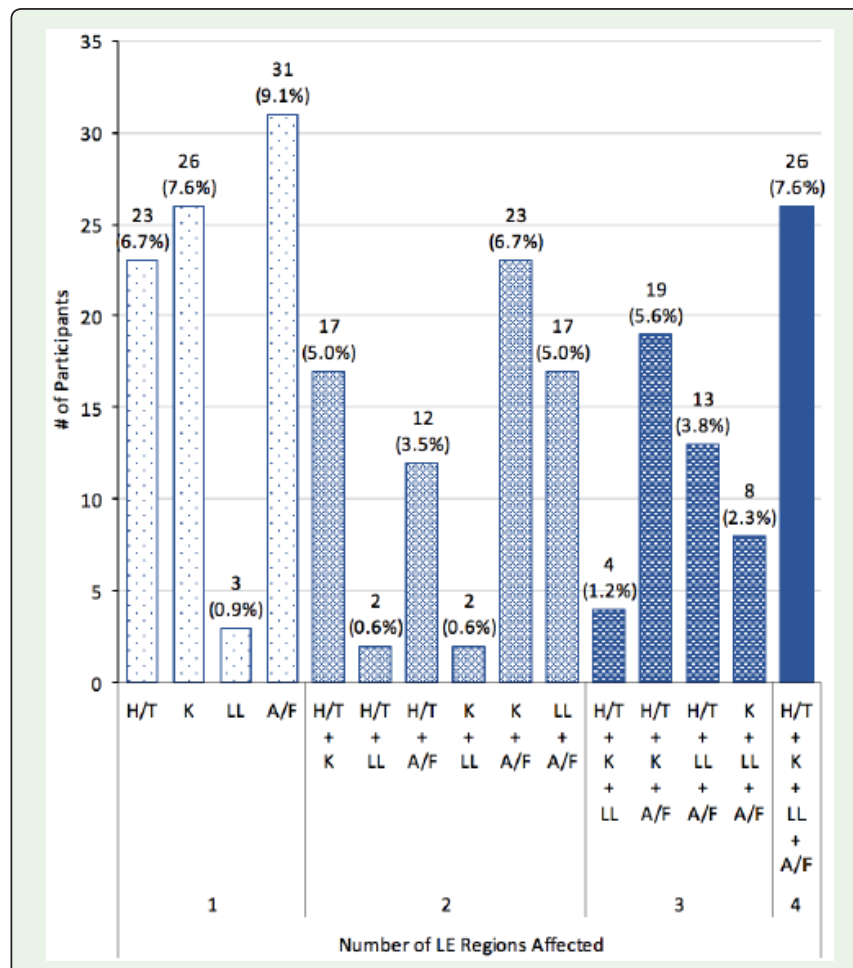

Figure 2: Distribution co-incident symptoms from the 226 participants reporting symptoms in one or more lower extremity (LE) regions $(\mathrm{H} / \mathrm{T}$ - Hip \& Thighs, K -Knees, LL- Lower Legs, A/F - Ankles \& Feet). 
portion of the sample indicated that the symptoms they experienced were from a traumatic injury. For each of the anatomic regions, approximately half of those experiencing symptoms had symptoms of moderate intensity. However, over 25 percent of those with hip, lower leg, or ankle/foot symptoms had intensity levels that were severe or extreme. For these same regions, over 80 percent indicated the symptoms worsened with work. For those reporting knee symptoms, this statistic was 72 percent. Seventy two to 90 percent, depending on anatomic region, reported that their discomfort worsened with work In comparison, few changed their job or duties or took sick leave due to their symptoms. More than a third of the sample reported relying on medication to alleviate symptoms and a little over 30 percent reported that they had seen a healthcare provider about their symptoms.

\section{Personal Characteristics}

Figure $4 \mathrm{a}$ shows that a greater percentage of females reported symptoms in the hip \&thighs $\left(\chi^{2}=4.1, \mathrm{p}=0.04, \mathrm{df}=1\right)$ as compared with males (43 vs 31 percent, respectively). There were also nonsignificant trends for a larger percentage of females to report symptoms in the lower leg and the ankles \& feet, compared to males.

A higher prevalence of hip \& thigh symptoms was seen (Figure $4 \mathrm{~b}$ ) in participants that identified themselves as either a current or past smoker as compared with the participants that never smoked $\left(\chi^{2}=6.8, p=0.009, \mathrm{df}=1\right)$. Similar non-significant trends were seen for the lower leg and the ankle $\&$ foot regions.

The data showed that increasing age was associated with a higher prevalence of symptoms (Figure 4c), particularly in the hip \& thigh region $\left(r^{2}=0.76\right)$. Symptom prevalence peaked for all anatomical regions, in the 46 to 55 year age group. The regression models showed a strong linear relationship between job tenure (Figure $4 \mathrm{~d}$ ) and lower leg symptoms $\left(r^{2}=0.91\right)$ and moderately strong linear relationships for the knee $\left(\mathrm{r}^{2}=0.52\right)$ and the hips \& thighs $\left(\mathrm{r}^{2}=0.46\right)$. It should be noted that there were no differences $(p>.05)$ in the mean age across the four job types described in table 2 .

Individuals in the normal BMI range showed the lowest percentage of symptoms in the ankle \& feet (Odd Ratio=2.12, Sensitivity $=55 \% /$ Specificity $=63 \%$ ), hip \& thighs (Odds Ratio $=1.66$, Sensitivity $=44 \% /$ Specificity $=68 \%$ ) ) and lower legs (Odds Ratio 2.54, Sensitivity $=57 \% /$ Specificity $=66 \%)$ ) as compared to those who were overweight or obese (Figure 4e). Although the modest sensitivity and specificity values show there is variability in these data. A much higher proportion of obesity was reported in the forklift drivers as compared to the other three job categories $\left(\chi^{2}=47.1, p=<.001, d f=3\right)$. However, no sufficient logistic regression models could be developed that included both BMI and job type suggesting that there is no interaction effect between these variables.

Participants with symptoms in the lower extremities were asked to indicate if their lower extremity discomfort was related to an underlying medical condition. The most commonly reported condition was sciatic nerve pain (3.2 percent) followed by knee osteoarthritis (2.6 percent).

\section{Symptom prevalence by job type}

Figure 5 shows that drivers of stand-up style forklifts showed a higher prevalence of symptoms in ankles \& feet as compared to those in the other distribution center job categories. While similar trends were seen in the knee and lower leg regions, these trends were not statistically significant. Those in walking jobs had relatively consistent rates of symptom reporting across each of the four anatomical regions sampled. The interaction effects between job type and age was also considered. This analysis did not show any effect, in part due to the lack of variability in age across job types. In sum, none of these analyses showed statistically significant effects.

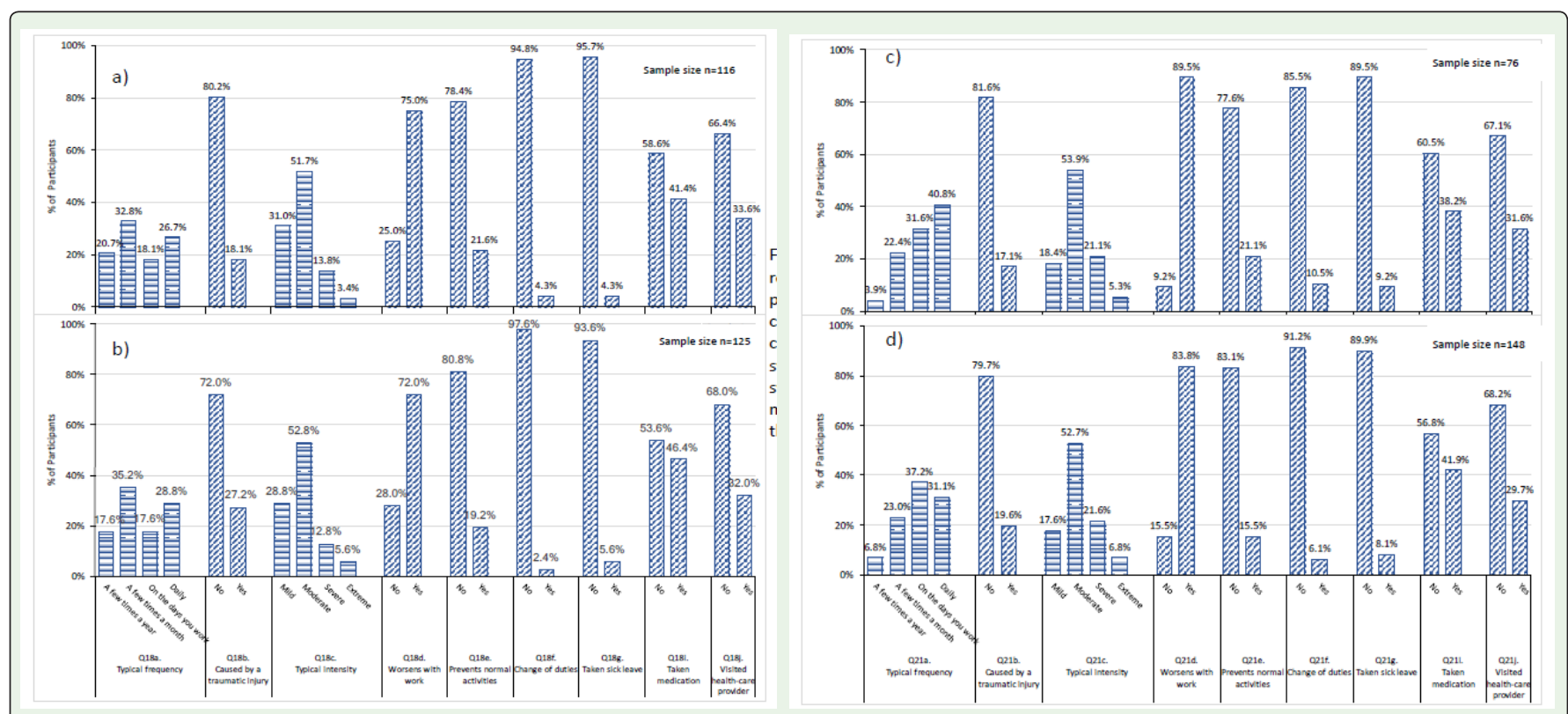

Figure 3: Distribution of responses to questions pertaining to frequency, cause, intensity and changes made due to the symptom for sample with symptoms in the past 12 months in the a) hip and thighs and b) knees. c) lowerlegs and d) ankles and feet. 


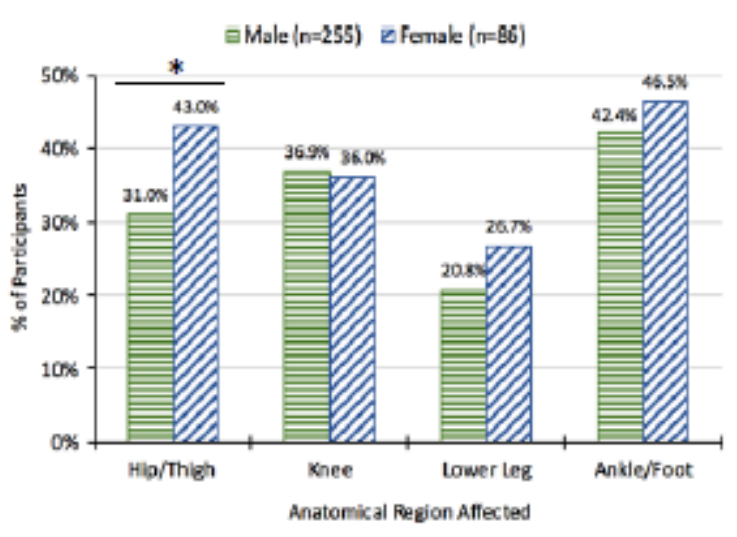

(a)

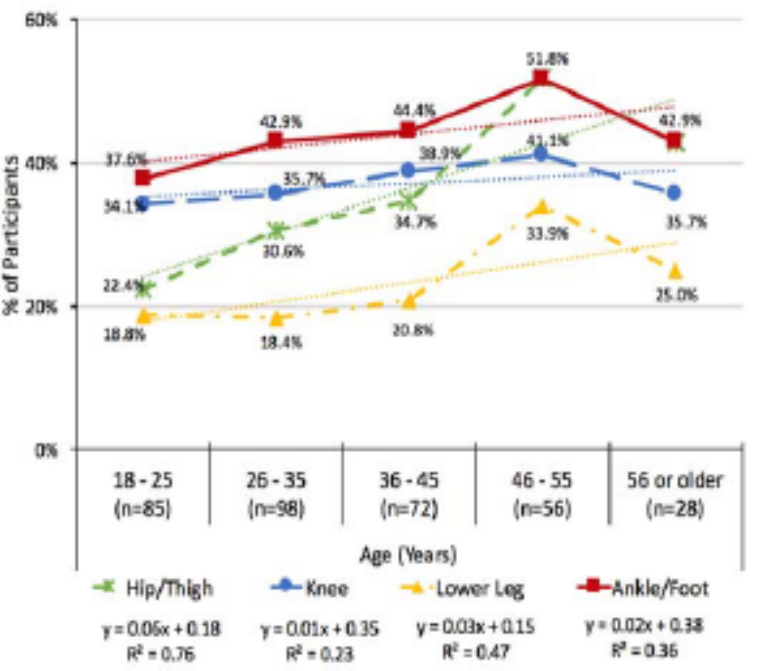

(c) a Never smoked ( $n=172) \quad$ ECurrent/Past smoker $(n=164)$

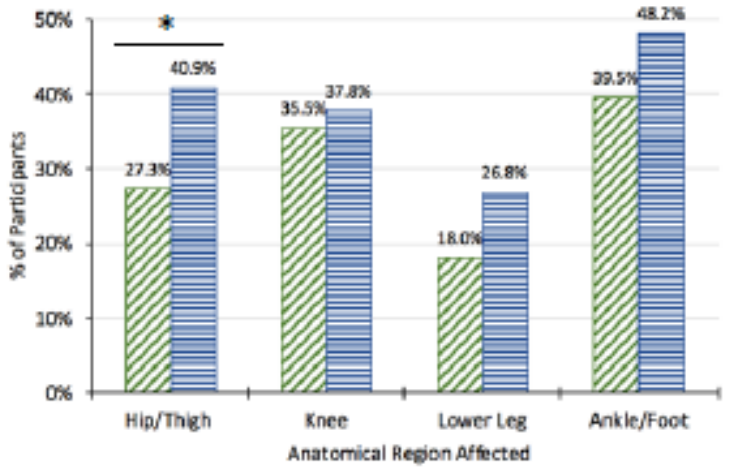

(b)

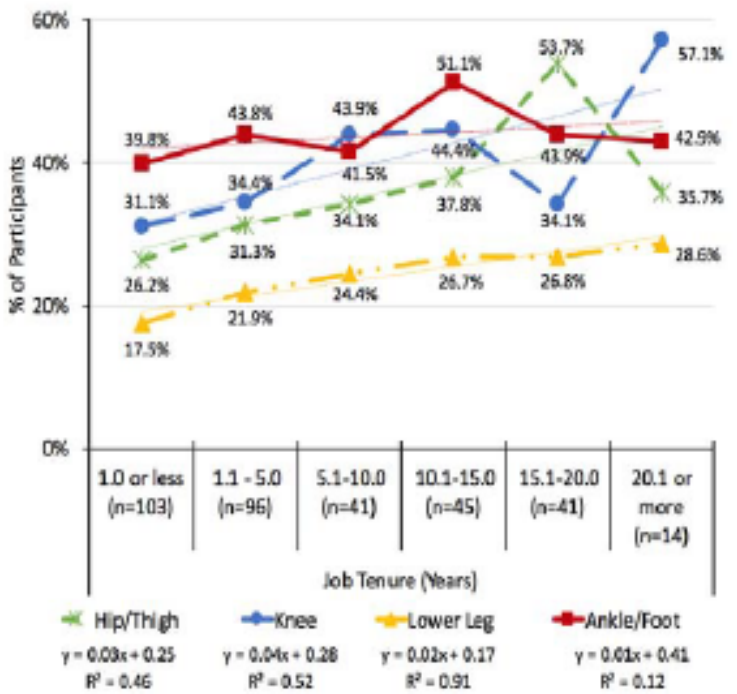

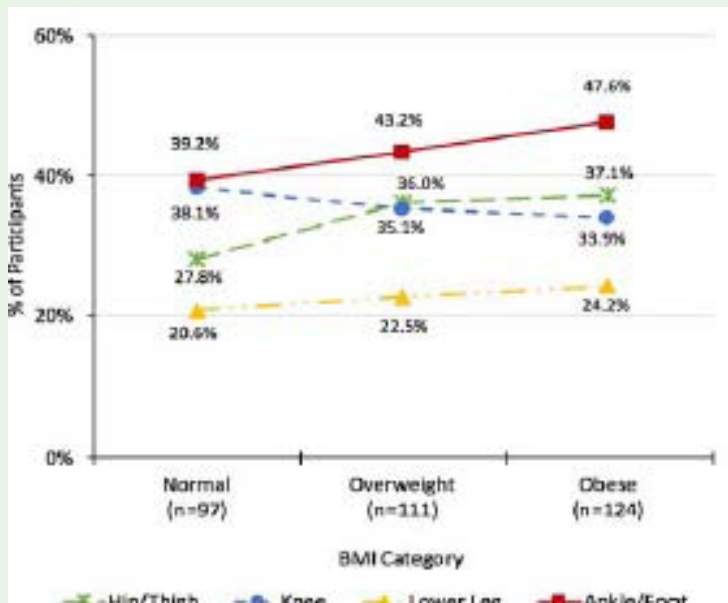

(d)

(e)

Figure 4: The prevalence of self reported lower extremity symptoms by anatomical region as a function of: (a) gender, (b) smoking status, (c) age, (d) job tenure, and (e) BMI. (Dotted lines indicate trend lines).

Citation: Dutt M, Lavender SA, Sommerich CM and Chaudhari AMW. The Prevalence of Lower Extremity Musculoskeletal Disorder Symptoms in Retail Distribution Centers. SM Musculoskelet Disord. 2018; 3(2): 1029.

https://dx.doi.org/10.36876/smmd.1029 


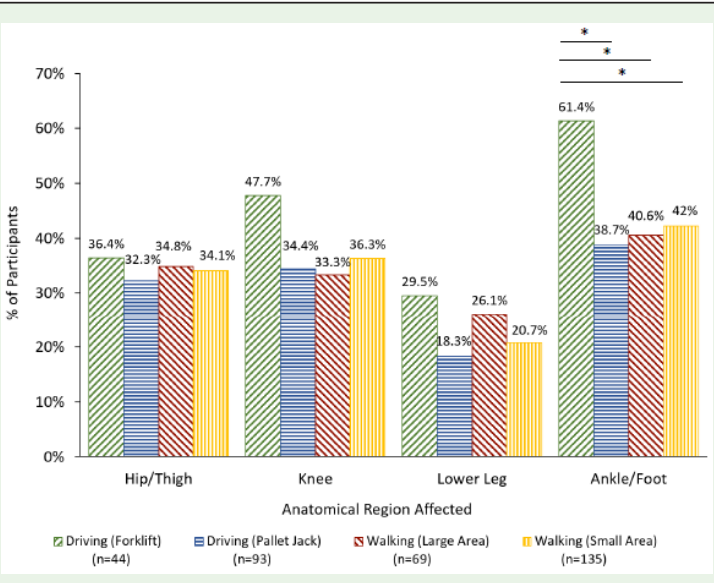

Figure 5: Distribution of participants who experienced lower extremity symptoms in the past 12 months by job type for driving jobs and walking jobs. (An "*" indicates statistically significant results of comparisons between job groups Chi-square test: $p<0.05)$ ).

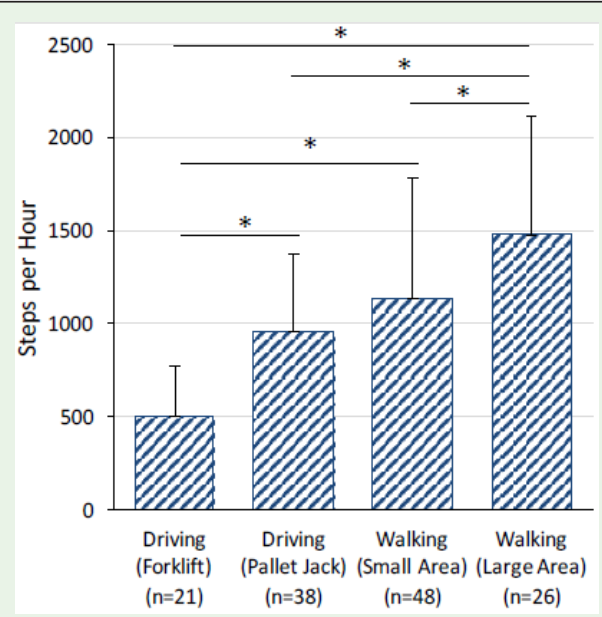

Figure 6: Comparison of mean steps taken per hour by participants categorized by job type.

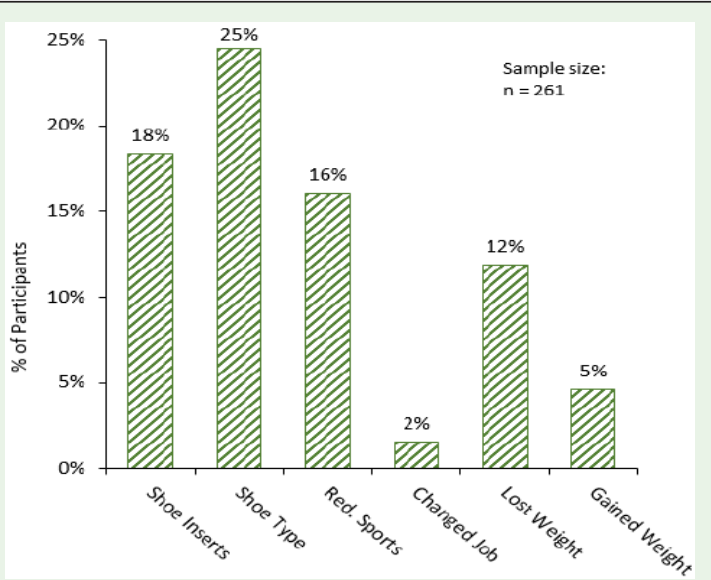

Figure 7: Changes made by participants after the onset of their lower extremity symptom. ("Red. Sports" = reducing participation in sports or other physical activities; "Changed Job"= Changed job, duties, or work schedule).

\section{Pedometer Sample}

The comparison of mean hourly steps taken by participant categorized by the four job types has been shown in Figure 6. Overall, those in the large area jobs showed the highest number of steps, followed by the small area walking jobs and the driving jobs. Forklift drivers had the lowest number of steps per hour.

\section{Changes made to alleviate symptoms in the lower extremities}

Participants who reported experiencing lower extremity discomfort were asked to indicate if they made any changes to alleviate their symptoms. The most common change was a change in shoe type, followed by the use of shoe inserts and reducing participation in sports (Figure 7).

\section{Discussion}

The findings of this study suggest that symptoms of MSDs in the lower extremities may be prevalent amongst material handlers in grocery and general merchandise retail distribution centers. Overall, approximately two-thirds of the participants in this study reported discomfort in one or more regions of the lower extremity within the past 12 months. These symptoms were reported across a variety of age groups and material handling jobs. Laboratory studies exist supporting the relationship between prolonged standing and lower limb discomfort $[16,17]$ and the effect of walking surfaces on lower extremity fatigue [18].

In this sample, ankle \& foot discomfort and symptoms were most prevalent followed by discomfort in the knee. In contrast, most of the literature has been focused on epidemiology of musculoskeletal symptoms and disorders of the hip and knee. One potential cause might be symptoms in the knees and hips are more severe and require days away from work and interventions by a healthcare provider as compared to symptoms in the ankles and feet.

Many of those in the current study who reported symptoms in their lower extremities also reported that their discomfort worsened with work. However, in comparison to the number reporting discomfort, very few changed their jobs and duties or took leave from work due to these symptoms. This is consistent with the low reporting of lower extremity symptoms in injury records (OSHA 300) relative to the frequency of back and upper extremity occupational MSDs. OSHA 300 refers to the "Log of Work-Related Injuries and Illnesses", a part of the federally required recordkeeping requirements for employers in the United Sates as prescribed by the Occupational Safety and Health Administration.

The following sections describe the associations between the reported symptoms and individual factors such as age, job tenure, gender, and smoking status and the associations between reported symptoms and the type of work performed.

\section{Symptom prevalence and workers' age}

Older workers had a higher prevalence of symptoms in the hip and thigh region. Previously, studies have included age as a risk factor 
for lower extremity MSD symptoms. deZwart et al. [14] found that 40 to 49 year olds were at higher risk of developing lower leg and ankle and foot symptoms as compared younger individuals. Manninen et al. [19] suggested that increasing age was a significant risk factor in developing knee osteoarthritis. An effect of increasing age on the number of symptoms has also been seen in other occupations such as physical therapists [20] and iron workers [21].

A smaller rate of reported symptoms by those who were 56 and older could be due to the "healthy worker survivor effect" [22]. In other words, an employee who has symptoms or discomfort related to their job would be more likely to change to a lower exposure job than those who are symptom-free. However, we only know the ages for those who elected to complete the survey. So we cannot rule out an alternative explanation that older individuals with symptoms were less willing to participate in the survey.

\section{Symptom prevalence and job tenure}

Employees who had worked for a greater number of years had a higher prevalence of lower leg, knee, and hip and thigh symptoms as compared to the newer employees. While there was only a very weak trend for increasing ankle and foot symptoms with increased job tenure, ankle and foot symptoms were generally the most prevalent overall.

Studies in the literature support the increase in symptom prevalence with years on the job. Yoshimura et al. [23] suggested greater than 1 year of job exposure in industrial works increased risk of knee OA. Croft et al. [24] studied the general population and concluded that those who handle loads that exceed $25 \mathrm{~kg}$ and worked more than 20 years were at an increased risk of hip OA. Pope et al. [9] concluded that people who walked more than 2 miles a day and had 15 or more years of this work exposure were at risk of developing hip/thigh symptoms. In contrast, walking more than 10,000 steps per day is encouraged for improvement in chronic health conditions such as cardiovascular disease, hypertension and diabetes. This disconnect between work exposures associated with lower extremity symptoms and the health guidelines of 10,000 steps could be due to the differences in environmental conditions experienced by workers in the material handling environment. Material handlers are walking on flooring surfaces such as concrete or experiencing the effects of vibration from driving material handling equipment such as forklifts and pallet jacks and the longer they are employed in such work environments, the higher the prevalence of symptoms.

\section{Symptom prevalence and gender}

As compared to males, females in the current study reported significantly higher symptom prevalence in the past 12 months in the hip \& thighs along with similar trends in the lower legs and ankles \& feet. This finding is consistent with Vingard et al.'s [8] study also reported an association between women who performed heavy lifting and lower extremity disorders. Messing et al. [25] concluded women workers had more lower leg, ankle and foot symptoms compared to men, even though a larger population of men stood at work, lifted heavier loads, worked longer work weeks and were more frequently exposed to whole body vibration. In the general population, Tuchsen et al. [26] found females have a higher risk than males of developing symptoms in the hip and thigh. While the current study found essentially no difference in the knee symptoms between men and women, this contrasts with Manninen et al. [19] who found associations between gender and knee symptoms. Like in literature, this study found women reported higher symptom prevalence as compared to men in all body parts except for the knee.

\section{Symptom prevalence and smoking status}

In the current study those who had never smoked had a lower prevalence of symptoms in the hip \& thighs as compared to the current/past smoker group. Numerous studies have found that smoking is a risk factor for low back pain [27-29], but very few studies were found that investigated the association between smoking with lower extremity pain and symptoms. For example, based on a crosssectional study, Brage et al. [30] reported a significant association between lower limb pain and smoking. Sherwin and Gastwirth [31] and Haverstock and Mandracchia [32] have also found associations between smoking and its detrimental effects on wound and bone healing in the lower extremities, respectively, leading to increased healing time and increased duration of pain and symptoms in smokers.

\section{Symptom prevalence and body mass index (BMI)}

The "Normal" BMI group showed a lower prevalence of symptoms in the ankle/feet, hip \& thighs and lower legs as compared to the "Overweight" group; and the highest prevalence of symptoms were seen in the "Obese" category. These were non-significant trends, but they are consistent with many studies that have shown obesity to be a risk factor for developing lower extremity musculoskeletal symptoms [11,33-37]. Riddle et al. [37] Concluded that there was a relationship between increasing BMI and risk of developing ankle and foot symptoms such as plantar fasciitis. Cooper et al. [33] indicated those with a BMI greater than 28 (overweight and obese) were at a risk for hip OA. Heliovaara et al. [34], who categorized BMI into groups of overweight, obese, and very obese individuals, showed increasing association between BMI and rheumatoid arthritis. Anderson and Felson [11] concluded that obese individuals were at a risk for development of knee OA. Coggon et al. [35] concluded that a high BMI along with kneeling and squatting postures increased risk of knee OA. Lau et al. [36] also concluded that there were associations between a person's body weight and their risk of developing knee OA. However, in contrast with the existing literature and unlike the other lower extremity regions, in the current study there was a lower prevalence of knee symptoms with higher BMI.

\section{Symptom prevalence and job type}

Previously, studies have shown associations between job type and the development of lower extremity musculoskeletal disorders. These risk factors are often associated with the distance the worker walks $[9,35]$ and the amount of time they spend driving [38-40] or lifting $[9,39]$.

As compared with the other job categories, forklift drivers showed significantly higher prevalence of symptoms in the ankles and feet, and similar trends for the knees and lower legs. In addition to stepping up and down from their equipment, forklift drivers are on their equipment for a majority of the day and exposed to whole body vibration. In this study, the forklift drivers were driving standup forklifts so the primary whole-body vibratory input is through 
their feet. Previous studies linking vibration to low back pain have mainly considered occupations with seated exposure, such as truck drivers [41]. Only one study was found linking whole body vibration to an increased risk of hip and thigh symptoms [26]. Lavender [42] reported findings from a small study where accelerometers attached to tibias of drivers operating stand-up forklift trucks showed reduced tibial shock exposures as the forklifts which had an operator isolated suspension system were driven in and out of trailers during receiving operations.

There were no significant differences in the prevalence of symptoms for those walking in large areas as compared to smaller areas. Excessive walking has been previously associated with the development of symptoms in the hips and knees. Pope et al. [9] suggested that walking more than 2 miles a day in addition to more than 15 years on the job is associated with hip and knee symptoms. It is important to note that individuals in the small walking area category, particularly those working inside trailers may be more inclined to twist their torsos during their work activities [42]. Miranda et al. [43] studied a population of forestry workers and found that moderately twisting the trunk (torso) can lead to persistent knee pain. Choobineh et al. [44] associated a twist at the trunk with ankle and foot symptoms and plantar fasciitis in nurses.

\section{Changes made by participants to alleviate discomfort and symptoms}

A majority of the participants indicated they had made changes to their shoe type and/or had added insoles to their shoes. Previous laboratory studies have indicated that shoe type and use of inserts or insoles can reduce fatigue and discomfort of the feet [18,45,]. Hence, a change in shoe type or the use of insoles may be a step in the right direction to reduce symptoms and fatigue. Given the relationship between BMI and symptom prevalence, it is notable that nearly 10 percent of the participants reported indicated losing weight as an approach taken to alleviate symptoms.

\section{Limitations}

The study used a cross-sectional design, which allowed for prevalence assessment of symptoms and personal factors relative to the jobs currently performed by the study participants. However, an inherent limitation of the design is that it does not allow the study of the temporal relationships between symptoms and potential risk factors including occupational exposures which may change as people shift between jobs within the facility. This can be addressed through future studies that have a longitudinal study design, therein allowing one to study personal and occupational factors in relation to development of symptoms over a period of time.

\section{Conclusion}

Two-thirds of the material handlers at the three distribution centers who participated in this study reported experiencing lower extremity musculoskeletal symptoms within the past 12 months. These were the most common in the ankles and feet (43.4 percent), while nearly one third of the participants reported symptoms in their knees and hip \& thighs. Stand-up forklift drivers have higher symptom prevalence in the ankles and feet and trends towards higher symptom reporting in the knees and lower legs. Significant associations between symptoms and variables such as age, gender, work experience and smoking status were also found indicating the contributions of individual factors. Given that a significant percentage of the study population had self-reported symptoms in the lower extremity, there is a need for further investigations to understand the causal pathways and potential control mechanisms that could improve worker health, turnover, absenteeism, and morale.

\section{Acknowledgement}

This project was supported by internal funds at The Ohio State University. This study investigated the prevalence of self-reported MSD symptoms in material handlers working at distribution centers.

Overall, nearly two thirds of the participants reported pain in one or more of places including their hips, knees, lower leg, and ankles/ feet. Older workers and forklift drivers had the highest prevalence rates.

\section{References}

1. The U.S. Bureau of Labor Statistics. News Release-Nonfatal occupational injuries and illnesses requiring days away from work, 2014.

2. Lavender SA, Mehta JP, Allread WG. Comparisons of tibial accelerations when walking on a wood composite vs. a concrete mezzanine surface. Applied Ergonomics. 2013; 44: 824-827.

3. Marras WS, Lavender SA, Ferguson SA, Splittoesser RE, Yang G Quantitative dynamic measures of physical exposure predict low back functional impairment. Spine. 2010a; 35: 914-923.

4. Marras WS, Lavender SA, Ferguson SA, Splittstoesser RE, Yang G. Quantitative biomechanical workplace exposure measures: Distribution centers. Journal of Electromyography and Kinesiology. 2010b; 20: 813-822.

5. Lavender SA, Marras WS, Ferguson SA, Splittstoesser RE, Yang G. Developing Physical Exposure Based Back Injury Risk Models Applicable to Manual Handling Jobs in Distribution Centers. Journal of Occupational and Environmental Hygiene. 2012; 9: 450-459.

6. Messing K, Tissot F, Stock SR. Lower limb pain, standing, sitting, walking: The importance of freedom to adjust one's posture. The International Ergonomics Association,Maastricht, Netherlands. 2006.

7. Andersen JH, Haahr JP, Frost P. Risk factors for more severe regional musculoskeletal symptoms. Arthritis and Rheumatism. 2007; 56: 1355-1364.

8. Vingard E, Alfredsson L, Goldie I, Hogstedt C. Occupation and osteoarthrosis of the hip and knee: a register-based cohort study. International Journal of Epidemiology. 1991; 20: 1025-1031.

9. Pope DP, Hunt JM, Birrell FN, Silman AJ, Macfarlane GJ. Hip pain onset in relation to cumulative workplace and leisure time mechanical load: a population based case-control study. Annals of the Rheumatic Diseases. 2003; 62: 322-326.

10. Sobti A, Cooper C, Inskip H, Searle S, Coggon D. Occupational physical activity and long-term risk of musculoskeletal symptoms: a national survey of post office pensioners. American Journal of Industrial Medicine. 1997; 32: 76-83.

11. Anderson JJ, Felson DT. Factors associated with osteoarthritis of the knee in the first national health and nutrition examination survey. American Journal of Epidemiology. 1988; 128: 179-189.

12. Felson DT, Nannan MT, Naimark A, Berkeley J, Gordon G, Wilson PW, et al. Occupational physical demands, knee bending, and knee osteoarthritis: results fromthe Framingham study. Journal of Rheumatology. 1991; 18: 1587-1592

13. McGlothlin JD. Ergonomic Interventions for the Soft Drink Beverage Delivery Industry. U.S. Department of Health and Human Services (NIOSH) Publication No. 1996; 96-109. 
14. de Zwart BC, Broersen JP, van der Beek AJ, Frings-Dresen MH. Occupational classification according to work demands: An evaluation study. Int J Occup Med Environ. 1997; 10: 283-295.

15. Dawson J, Thorogood M, Marks S, Juszczak E, Dodd C, Lavis G. The prevalence of foot problems in older women: A cause for concern. J Public Health Med. 2002; 24: 77-84

16. Ryan G. The prevalence of musculoskeletal symptoms in supermarket workers. Ergonomics. 1989; 2: 570-581.

17. Madeleine P, Voigt M, Arendt-Nielsen L. Subjective, physiological, and biomechanical responses to prolonged manual work performed standing on hard and soft surfaces. European Journal of Applied Physiology. 1998; 77 $1-9$

18. Redfern MS, Chaffin DB. Influence of flooring on standing fatigue. Human Factors. 1995; 37: 570-581.

19. Manninen P, Heliovaara M, Riihimaki H, Suoma-lainen O. Physical workload and the risk factors of severe knee osteoarthritis. Scandinavian Journal Work Environment and Health. 2002; 28: 25-32.

20. Cromie JE, Robertson VM, Best MO. Work-related musculoskeletal disorders in physical therapists: Prevalence, severity, risk and responses. Physical Therapy. 2000; 80: 336-351.

21. Forde MS, Punnett L, Wegman DH. Prevalence of musculoskeletal disorders in union ironworker Journal of Occupational and Environmental Hygiene. 2005; 2: 203-212.

22. Arrighi HM, Hertz-Picciotto I. The Evolving Concept of the Healthy Worker Survivor Effect. Epidemiology. 1994; 5: 189-196.

23. Yoshimura N, Nishioka S, Kinoshita H, Hori N, Nishioka T, Ryujin M. Risk factors for knee osteoarthritis in Japanese women: heavy weight, previous joint injury and occupational activities. Journal of Rheumatism. 2004; 31 157-162.

24. Croft P, Cooper C, Wickham C, Coggon D. Osteoarthritis of the hip and occupational activity. Scandinavian Journal of Work Environment and Health. 1992; 18: 59-63.

25. Messing K, Tissot F, Stock S. Distal lower-extremity pain and work postures in the Quebec population. American Journal of Public Health. 2008; 98 705-713.

26. Tuchsen F, Hannerz N, Burr H, Lund T, Krause, N. Risk factors predicting hip pain in a 5-year prospective cohort study. Scand J Work Environ Health. 2003; 29: 35-39.

27. Deyo RA, Bass JE. Lifestyle and low-back pain. The influence of smoking and obesity. Spine. 1989; 14: 501-506.

28. Frymoyer JW, Pope MH, Costanza MC, Rosen JC, Goggin JE, Wilder DG Epidemiologic studies of low-back pain. Spine. 1980; 5: 419-423.

29. Heliovaara M, Makela M, Knekt P, Impivaara O, Aromaa A. Determinants of sciatica and low back pain. Spine. 1991; 16: 608-614.

30. Brage S, Bjerkedal T. Musculoskeletal pain and smoking in Norway. Journal of Epidemiology and Community Health. 1996; 50: 166-169.
31. Sherwin MA, Gastwirth CM. Detrimental effects of cigarette smoking on lower extremity wound healing. Journal of Foot Surgery. 1990; 29: 84-87.

32. Haverstock BD, Mandracchia VJ. Cigarette smoking and bone healing: implications in foot and ankle surgery. Journal of Foot and Ankle Surgery. 1998; 37: 69-74.

33. Cooper C, Inskip H, Croft P, Campbell L, Smith G, McLaren M, et al. Individual risk factors for hip osteoarthritis: Obesity, injury, and physical activity. Am J Epidemiol. 1998; 147: 516-522.

34. Heliovaara M, Makela M, Impivaara O, Knekt P, Aromaa A, Sievers K. Association of overweight, trauma, and workload with coxarthrosis. Acta Orthopaedica Scandinavica. 1993; 64: 613-618.

35. Coggon D, Croft P, Kellingray S, Barrett D, McLaren M, Cooper C. Occupational physical activities and osteoarthritis of the knee. Arthritis and Rheumatism. 2000; 43: 1443-1449.

36. Lau EC, Cooper C, Lam D, Chan VNH, Tsang KK, Sham A. Factors associated with osteoarthritis of the hip and knee in Hong Kong Chinese: Obesity, joint injury and occupational activities American Journal of Epidemiology. 2000; 152: 855-862.

37. Riddle DL, Pulisic M, Pidcoe P, Johnson RE. Risk factors for plantar fasciitis: A matched case-control study. The Journal of Bone and Joint Surgery. 2003; 85-A: 872-877.

38. Yoshimura N, Sasaki S, Iwasaki K, Danjoh S, Kinoshita H, Yasuda T, et al Occupational lifting is associated with hip osteoarthritis: A Japanese casecontrol study. Journal of Rheumatology. 2000; 27: 434-440.

39. Sobti A, Cooper C, Inskip H, Searle S, Coggon D. Occupational physical activity and long-term risk of musculoskeletal symptoms: a national survey of post office pensioners. American Journal of Industrial Medicine. 1997; 32 $76-83$

40. Chen JC, Dennerlein JT, Shih TS, Chen CJ, Cheng Y, Chang, WP, et al. Knee pain and driving duration: a secondary analysis of the taxi drivers' health study. American Journal of Public Health. 2004; 94: 575-581.

41. Robb MJM, Mansfield NJ. Self-reported musculoskeletal problems amongst professional truck drivers. Ergonomics. 2007; 50: 814-827.

42. Lavender SA. Evidence-Based Ergonomics: Interventions for DCs. Warehouse Education and Research Council Annual Conference, Providence, R.I. 2016.

43. Miranda $\mathrm{H}$, Viikari-Juntura E, Martikainen R, Riihimaki $\mathrm{H}$. A prospective study on knee pain and its risk factors. Osteoarthritis and Cartilage. 2002; 10: 623630.

44. Choobineh A, Rajaeefard A, Neghab M. Association between perceived demands and musculoskeletal disorders among hospital nurses of Shiraz University of Medical Sciences: a survey questionnaire. International Journal of Occupational Safety and Ergonomics. 2006; 12: 409-416.

45. Lafortune MA, Hennig EM. Cushioning properties of footwear during walking: accelerometer and force platform measurements. Clin Biomech. 1992; 7 : 181-184. 